Goldschmidt 2021 Abstract

https://doi.org/10.7185/gold2021.4758

\section{Interface versus internal recycling of organic matter in coastal sediments: a case study from two RioMars - the Louisiana shelf and the Rhône prodelta}

CHRISTOPHE RABOUILLE ${ }^{1}$, BRUNO LANSARD ${ }^{2}$, NANCY N RABALAIS ${ }^{3}$, SHANNON M. OWINGS ${ }^{4}$, JENS RASSMANN $^{2}$, BRUNO BOMBLED ${ }^{5}$, EDOUARD METZGER $^{6}$, JORDON BECKLER ${ }^{7}$ AND MARTIAL TAILLEFERT $^{4}$

\section{${ }^{1}$ LSCE CEA/CNRS/UVSQ}

${ }^{2} \mathrm{LSCE}$

${ }^{3}$ Louisiana State University

${ }^{4}$ Georgia Institute of Technology

${ }^{5}$ LSCE -CNRS

${ }^{6}$ LPG-BIAF, Université d'Angers

${ }^{7}$ Florida Atlantic University

Presenting Author: rabouill@1sce.ipsl.fr

Sediments are known to be a major location of organic matter $(\mathrm{OM})$ recycling in coastal areas, therefore contributing to active recycling of nutrients and the overall productivity of the global coastal ocean. The recycling of organic matter in bottom waters and sediments also generates alarming biogeochemical processes in the coastal zone: deoxygenation (also known as hypoxia) and acidification. Bottom water hypoxia and coastal acidification are linked to increased organic matter sedimentation and oxic remineralization in stratified bottom waters, which consumes oxygen and generates additional ocean acidification by the production of metabolic $\mathrm{CO}_{2}$. Yet, the interaction between recycling in the water column and sediments is not well understood and quantified. This is especially the case of anoxic recycling of $\mathrm{OM}$, of burial of reduced substances and of the carbonate precipitation/dissolution influence on the carbon mass balance. Specifically, the role of interface (sediment surface) versus internal (deeper in sediments) recycling is questioned relative to the balance of oxic/anoxic recycling. In this presentation, we try to establish the biogeochemical influence of both type of recycling on hypoxia and acidification in bottom waters.

To illustrate the contrast, we investigated two different locations: The Louisiana shelf (LS) near the Mississippi River in the northern Gulf of Mexico and the Rhône prodelta (RP) in the Mediterranean Sea. The LS is one of the largest seasonal hypoxic zones of the coastal ocean with associated acidification, whereas the RP is a rapidly accumulating deltaic region. By combining dissolved inorganic carbon (DIC), total alkalinity (TA), sulfate, and oxygen concentration profiles together with benthic fluxes, we show that the two contrasted regions are characterized by very different features: In the LS, sediment diagenesis is generally weak, with limited sulfate depletion and DIC increase at depth in sediments, but high mineralization at the sedimentwater interface (Rabouille et al., 2021). On the contrary, the RP sediments are characterized by intense internal anoxic diagenesis inducing FeS production and net alkalinity production and fluxes (Rassmann et al., 2020). We show how these two modes of recycling can impact water column oxygen and $\mathrm{pH}$ levels in the coastal ocean. 